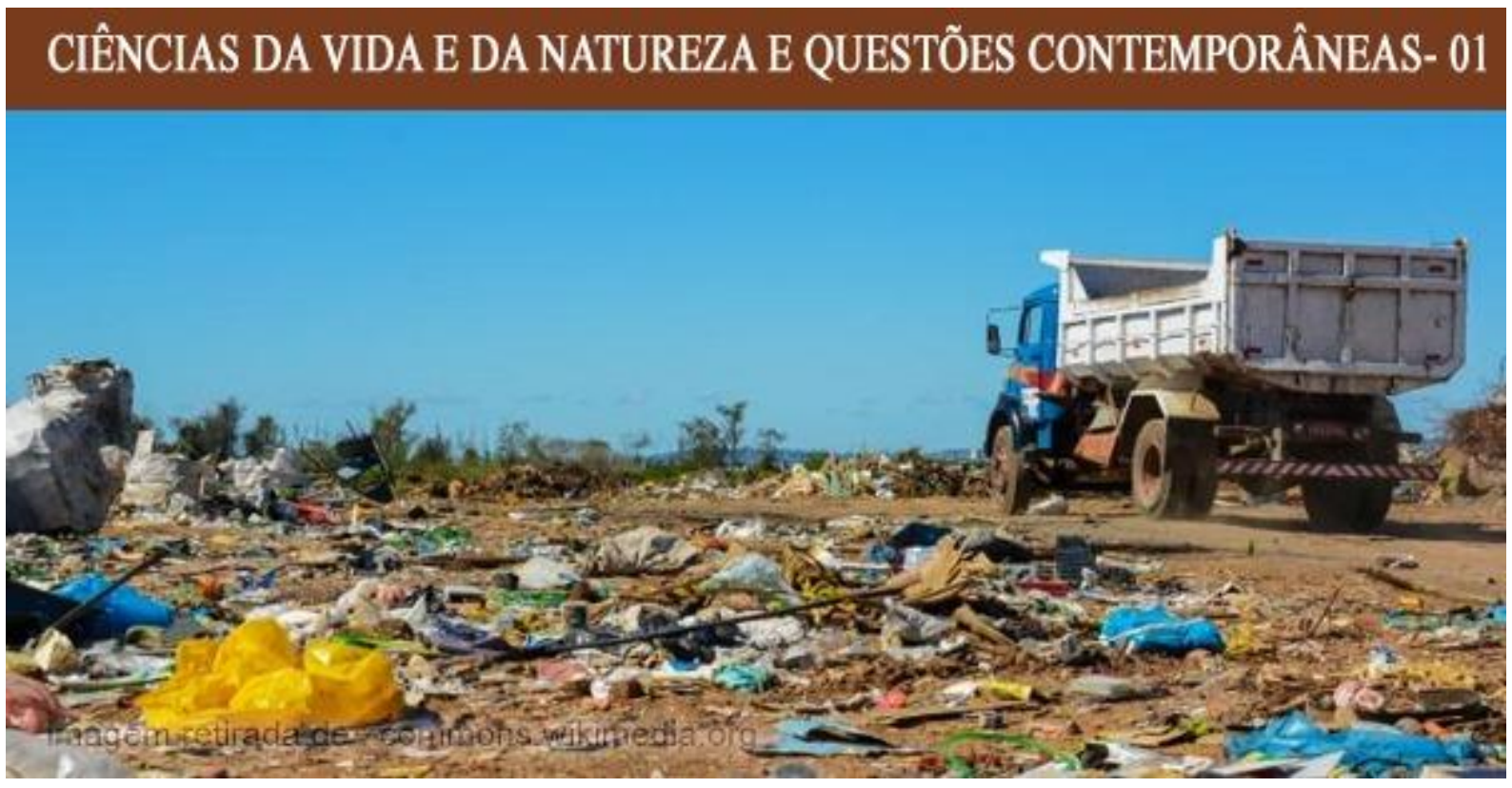

\title{
A IMPORTÂNCIA DA GESTÃO INTEGRADA DOS RESÍDUOS SÓLIDOS: O CASO DAS CARGAS DE RESÍDUOS DOMICILIARES RURAIS DE SANTA CRUZ DO SUL - RS
}

\author{
Ismael Fernando Christmann \\ ORCID: https://orcid.org/0000-0002-9989-423X. \\ E-mail: ichristm@hotmail.com. \\ Dilani Silveira Bassan \\ ORCID: https://orcid.org/0000-0002-2223-9827. \\ E-mail: bassandilani@gmail.com.
}

Resumo: O consumo, aliado à industrialização, a cada ano produz muitos tipos de novos produtos e embalagens. Junto a isso, a distribuição e a logística vêm alcançando locais cada vez mais remotos, fazendo com que áreas rurais disponham dos mesmos produtos existentes nas áreas urbanas. A preocupação com esse avanço é a disposição final desse material, ou o gerenciamento dos resíduos sólidos domésticos nessas áreas. Os custos desse processo podem trazer obstáculos à sua realização. Dessa forma, esta pesquisa objetiva demonstrar algumas dificuldades sobre a gestão integrada de resíduos sólidos, principalmente pela análise da área rural de Santa Cruz do Sul. Identificou-se que o resíduo doméstico rural transportado pelos caminhões não era pesado, apenas registrada a entrada dos caminhões, dificultando o entendimento da eficiência desse atendimento. Assim, uma discrepância pode passar despercebida pelos gestores, pois o município de Santa Cruz do Sul/RS não possui uma área rural muito extensa. Para poder observar esse processo, foram rastreados dados entre os anos de 2007 à 2015 , através de pesquisas bibliográficas e documentais. Foi possível verificar que o número de cargas das áreas rurais vem aumentado, sem alteração na população rural como também sem aumento de produção das embalagens. Além disso, os valores cobrados por esse transporte a cada ano se tornam mais caros. Portanto, para ter uma gestão transparente e políticas públicas eficientes, faz-se necessário disponibilizar e analisar os dados e valores sobre a produção de resíduos sólidos de forma clara e objetiva, com a elaboração de um processo que seja eficaz enquanto medida socioambiental.

Palavras-chave: Gestão de Resíduos. Resíduo Doméstico Rural. Custo dos Resíduos.

\section{POLÊM!CA $\mid$ LABORE (3)}

Polêmica - Revista Eletrônica da Uerj - Rua São Francisco Xavier, 524, $1^{\circ}$ andar bloco D, sl.1001 • Tels.: +55 21 2334-4088 / 4087 • http://www.e-publicacoes.uerj.br/index.php/polemica/index http://www.labore.uerj.br • laboreuerj@yahoo.com.br 


\title{
THE IMPORTANCE OF THE INTEGRATED SOLID WASTE MANAGEMENT: THE CASE OF THE RURAL HOUSEHOLD WASTE LOADS IN SANTA CRUZ DO SUL - RS
}

\begin{abstract}
The consumerism allied to industrialization each year produces many kinds of new products and packaging. Together, the distribution and the logistics are reaching places increasingly remote, so that the rural areas can have the same products that the urban areas do. The concern on this advance is the final disposal of this material or the domestic solid waste management in these areas. The costs of this process can bring some difficulties for the realization of this type of collection. This research was done to demonstrate some difficulties about the integrated solid waste management, mainly through the analysis of the rural area of Santa Cruz do Sul. It was identified that the rural domestic waste transported by trucks was not weighed, only registered the entry of trucks, making it difficult to understand the efficiency of this attendance. Therefore, this discrepancy can go unnoticed by the managers, because the city of Santa Cruz do Sul/RS does not have a very large rural area. To observe these procedures, it tracked data between the years of 2007 to 2015, through bibliographical and documental research. Thus, it was possible to verify that the number of loads from the rural areas is increasing, without an alteration on the rural population, but also without increasing packaging production. In addition, the costs charged for this transportation become more expensive each year. Therefore, in order to have a transparent management and efficient public politics, it is necessary to make available and analyze the data and values about the solid waste production in a clear and objective way, with the elaboration of a process that is effective as a socio-environmental measure.
\end{abstract}

Keywords: Waste Management. Rural Domestic Waste. Waste Cost.

\section{Introdução}

A partir de 2010, ano da promulgação da nova Política Nacional de Resíduos Sólidos PNRS (2010), os municípios passaram a ter a obrigação de uma gestão mais responsável dos seus resíduos sólidos. Essas novas responsabilidades vêm ao encontro de todo um movimento mundial em busca de um equilíbrio entre economia e meio ambiente, gerando uma maior sustentabilidade para o planeta. Por isso, é necessário repensar os processos de geração, reaproveitamento e destinação final dos resíduos, para que o impacto sobre o meio ambiente seja o menor possível. Isso porque sabe-se que os recursos naturais são finitos, e a capacidade de incorporar as modificações realizadas pelo homem no meio ambiente fica restrita ao que o meio ambiente reconhece como matéria orgânica.

Conforme dados do Instituto Brasileiro de Geografia e Estatística - IBGE (2010), 19\% da população brasileira reside em áreas rurais. No Estado do Rio Grande do Sul, a população concentrada em áreas consideradas rurais fica próxima dos 18\% e em Santa Cruz do Sul, lócus desta pesquisa, conforme o Plano Municipal de Gestão Integrada de Resíduos Sólidos PMGIRS (2013), 11,08\% da população habita em localidades rurais.

A população de Santa Cruz do Sul que reside nessas áreas é menor que a média estadual e nacional, mas, mesmo assim, é uma parcela significativa da população. Apesar das projeções apontarem para um esvaziamento da população rural, as quantidades de resíduo geradas nessas áreas são consideráveis. Deve-se, então, atentar para o manejo dos resíduos rurais, pois, se não

\section{POLÊM!CA $\mid$ LABORE}

Polêmica - Revista Eletrônica da Uerj - Rua São Francisco Xavier, 524, $1^{\circ}$ andar bloco D, sl.1001 • Tels.: +55 21 2334-4088 / 4087 • http://www.e-publicacoes.uerj.br/index.php/polemica/index http://www.labore.uerj.br • laboreuerj@yahoo.com.br 
forem gerenciados, podem acabar contaminando o meio ambiente e o ciclo produtivo das culturas cultivadas, além das nascentes de rios e arroios e seus afluentes.

Portanto, com o intuito de analisar a gestão de resíduos sólidos local e sua eficácia, propôs-se verificar a quantidade de resíduos produzida no meio rural de Santa Cruz do Sul, bem como seu destino. Tomou-se a seguinte questão problema: qual a quantidade de cargas realizada na área rural de Santa Cruz do Sul e qual é o peso destas cargas? Como parâmetro para a investigação, utilizou-se o que está disposto no PMGIRS a fim de averiguar se é cumprido o que está determinado no documento em prol de uma gestão sustentável.

Conforme Darolt (2008), o resíduo rural, além de ser composto por restos vegetais da cultura, que podem ser reutilizados como adubo e absorvidos novamente pelo solo, também é composto por materiais associados à produção agrícola, como adubos químicos, defensivos e suas embalagens, dejetos animais, produtos veterinários, peças metálicas, e por sobras domiciliares, semelhantes às produzidas nas cidades, como restos de alimentos, vidros, latas, papéis, papelões, plásticos, pilhas e baterias, lâmpadas etc., que devem ser descartados corretamente para não causar impactos ao meio ambiente.

$\mathrm{O}$ aumento dos produtos industrializados que o consumismo vem implantando, aliado à capacidade de distribuição das empresas, com o crescimento na produção de embalagens, faz com que as populações rurais tenham acesso aos mesmos produtos que a população urbana dispõe, ampliando a dificuldade para a correta disposição destes resíduos. Como já sinalizado, o descarte errôneo pode acarretar a contaminação nessas áreas.

É com essa preocupação que analisou-se a gestão de resíduos sólidos nas áreas rurais em Santa Cruz do Sul, a partir de dados do PMGIRS-SCS e dados pesquisados na Usina de Triagem do município, para onde se destina o resíduo coletado na área rural. Investigar a eficácia desse processo, pode apontar para fragilidades e caminhos que ainda devem ser percorridos para o desenvolvimento sustentável.

\section{Metodologia}

Como delimitação da pesquisa, tomou-se por base as coletas da área rural do município de Santa Cruz do Sul/RS, Brasil. E como recorte temporal será utilizada a análise e comparações de dados entre os anos de 2007 à 2015, administrações dos prefeitos: José Alberto Wenzel

\section{POLÊM!CA $\mid$ LABORE}

Polêmica - Revista Eletrônica da Uerj - Rua São Francisco Xavier, 524, $1^{\circ}$ andar bloco D, sl.1001 • Tels.: +55 21 2334-4088 / 4087 • http://www.e-publicacoes.uerj.br/index.php/polemica/index http://www.labore.uerj.br • laboreuerj@yahoo.com.br 
(01/01/2005 à 19/06/2008), Helena Hermany (26/06/2008 à 31/12/2008), Neiva Teresinha Marques (01/01/2009 à 31/12/2012) e Telmo José Kist (01/01/2013 à 31/12/2016).

A partir disso foi realizada a coleta de dados através de pesquisa bibliográfica e documental. Segundo Leopardi (2001), a coleta de dados não é um processo cumulativo e linear, mas um processo de ir e vir, de interação entre os sujeitos que vivem uma dada experiência e são baseados em uma racionalidade de comunicação entre eles.

Foram consultados documentos em formato eletrônico e impresso, como registros de produção e registros administrativos - tabelas e planilhas eletrônicas -, além de atas e relatórios produzidos pela Cooperativa de Catadores e Recicladores de Santa Cruz do Sul - COOMCAT, e também de planos, leis, licitações e documentos disponibilizados pela prefeitura de Santa Cruz do Sul, como o PMGIRS mais recente, datado de 2013. Já a pesquisa bibliográfica tratou de levantar produções literárias ligadas à temática da gestão de resíduos sólidos, que tiveram como objetivo permitir o reforço paralelo na análise das informações.

\section{A Gestão Integrada dos Resíduos Sólidos}

Com o volume cada vez maior de lixo sendo gerado, os antigos locais de disposição, os famosos lixões, produziam contaminações na natureza, afetavam a população próxima, como também toda a sociedade. Por isso, conforme Tchobanoglous (1993 apud REICHERT, 1999), nas décadas de 1980 e 1990, várias ações foram propostas para reverter essa realidade. No Brasil, são exemplos a implantação de coleta seletiva em Niterói/RJ, em 1985 (EIGENHEER, 2009), e as construções de aterros para resíduos inertes em São Paulo, em São Mateus e Itatinga, entre 1989 e 1993 (JACOBI, 2006). Nesse contexto, o modelo mundialmente mais adotado baseia-se na Gestão Integrada de Resíduos Sólidos, na qual todos os elementos fundamentais, além das interfaces e conexões entre os diferentes componentes, são avaliados e utilizados para se conseguir a solução mais eficaz e econômica. Nesse caso, um Plano de Gestão de Resíduos deve ser configurado para que sua aplicação seja usual e tenha avanço e controle sobre o resíduo gerado.

Esse gerenciamento possui o objetivo da redução, do reaproveitamento e da reciclagem dos resíduos. É uma iniciativa do poder público, que tenta resolver o problema dos resíduos não só nos centros urbanos, mas também nas áreas rurais, para, assim, minimizar a quantidade de resíduos para a disposição final. Mas, mesmo diante de uma eficaz aplicação do processo,

\section{POLÊM!CA $\mid$ LABORE}

Polêmica - Revista Eletrônica da Uerj - Rua São Francisco Xavier, 524, $1^{\circ}$ andar bloco D, sl.1001 • Tels.: +55 21 2334-4088 / 4087 • http://www.e-publicacoes.uerj.br/index.php/polemica/index http://www.labore.uerj.br • laboreuerj@yahoo.com.br 
haverá, ainda, sobras ou rejeitos que serão encaminhados ao aterro sanitário, que possui um tempo limitado de uso (ZANETI, 2006). Ainda assim, sua adoção é de extrema relevância, devendo envolver toda a população.

\begin{abstract}
No sistema de gestão de resíduos, a população percebe que as dimensões, social, econômica e ambiental, estão articuladas e, que, participar da coleta seletiva é muito importante neste processo. Se, ao contrário, as pessoas perceberem que o interesse econômico privado prevalece no sistema de gestão, o caráter socioambiental do sistema se perde e a população pode vir a não se engajar na coleta seletiva porque o interesse deixa de ser coletivo para ser privado. (ZANETI, 2006, p. 220).
\end{abstract}

Seu planejamento deve ser elaborado diante das realidades presenciadas no local que abrangerá o seu gerenciamento. Segundo Zaneti (2006), a expressão "gestão integrada" é mundialmente usada, mas seu conteúdo ainda é vago e múltiplo, segundo as conveniências de quem a utiliza. Isso serve, também, para o termo gestão "socialmente" integrada, pois é extremamente variável, principalmente quanto à importância do social e, particularmente, do emprego e da participação, de acordo com cada país.

Nesse contexto, é relevante discutir a produção e a gestão dos resíduos nas regiões rurais. Barbosa (2005) contribui, afirmando que a área rural fica restrita ao desenvolvimento de atividades exclusivamente agrícolas, mas, atualmente, possuem dinâmicas semelhantes com as áreas centrais das cidades, na relação produção e consumo. Por vezes, esses espaços são considerados uma continuação da área urbana. Por isso, Pedroso (2010) constata que, hoje, a facilidade de deslocamento dos moradores das áreas rurais, aliada à mudança comportamental em relação às compras, principalmente pelo acesso para a aquisição de todo e qualquer material de consumo, gera, nas áreas rurais, um aumento significativo da quantidade de resíduos.

No passado, os resíduos rurais eram, em sua maioria, constituídos por matéria orgânica, que degradavam e se incorporavam ao solo mais rapidamente. Mas, com o avanço do consumismo, isso se modificou. A maior parte dos resíduos produzidos hoje é de natureza inorgânica (embalagens plásticas, vidros, produtos químicos, etc.), que levam muito tempo para se degradarem, causando maiores impactos e devastações (ROCHA, 2012).

Conforme descreve Pedroso (2010), o resíduo doméstico mal descartado pode acarretar vários problemas nas propriedades rurais. Quando não é recolhido e armazenado adequadamente em um depósito, pode ser um chamativo para roedores, insetos voadores e rasteiros, os quais farão dele o seu sustento, transformando em seu abrigo as casas e galpões da propriedade. Além disso, a queima de resíduos - uma prática comum nas áreas rurais - também

\title{
POLÊM!CA $\mid$ LABORE
}

Polêmica - Revista Eletrônica da Uerj - Rua São Francisco Xavier, 524, $1^{\circ}$ andar bloco D, sl.1001 • Tels.: +55 21 2334-4088 / 4087 • http://www.e-publicacoes.uerj.br/index.php/polemica/index http://www.labore.uerj.br • laboreuerj@yahoo.com.br 
não pode ser considerada um tratamento adequado, pois pode provocar incêndios, a emissão de gases poluentes e a perda das propriedades nutricionais do solo onde se realiza. Em contrapartida, uma boa prática nas áreas rurais, é a reutilização de materiais, como garrafas e potes de plástico e embalagens de metais, que servem para transportar leite ou para armazenar sementes (SOARES et al., 2013).

Ainda assim, apesar dos impactos apresentados, as alterações ocasionadas pela disposição inadequada de resíduos domésticos nas áreas rurais acabam sendo muito menores que as produzidas pelos "lixões" das áreas urbanas. No entanto, devem ser levadas em consideração, pois, em alguns casos, essas disposições são alocadas em espaços distantes da ocupação do homem e acabam nunca sendo observadas para uma eventual recuperação ambiental, ao contrário da área urbana (NOBRE, 2009).

A conscientização da população residente na área rural é de alta prioridade, pois esta
acredita que, por ser pouca quantidade de lixo produzida por ela, não afetará o meio
ambiente. Na maioria dos casos, o recolhimento do lixo é inviável para o poder
público, nesse caso, o agente responsável, ou seja, a população, decide sobre a
destinação final desses resíduos. (ROCHA, 2012).

Por isso, Rocha (2012) afirma que a compreensão sobre a problemática dos resíduos sólidos, pelos moradores da área rural, é de suma importância para modificar a forma de pensar e de agir frente aos problemas ambientais. As práticas nesse meio social é que irão determinar a magnitude e a natureza dos problemas ambientais que assolam a sociedade. Dessa forma, surge a necessidade da prática da Gestão Ambiental, em que atue o poder público.

O acesso a bens industrializados, entretanto, vem aumentando e, consequentemente,
também vem crescendo a presença de resíduos não orgânicos nos resíduos rurais.
Nesse sentido, a participação de produtos que geram resíduos perigosos - como
baterias, lâmpadas fluorescentes, embalagens de produtos químicos etc. - também se
vem ampliando. Por este motivo, é importante que os governos locais desenvolvam
estratégias de coleta e tratamento, mesmo com uma frequência inferior àquela adotada
em áreas urbanas, para atender os domicílios localizados em áreas rurais. (IPEA,
2012, p. 16).

Segundo o Instituto de Pesquisa Econômica Aplicada - Ipea (2012), é alarmante a comparação da coleta dos municípios urbanos com a coleta dos resíduos rurais, pois somente alcança a metade da taxa de cobertura das áreas urbanas nas Regiões Sul e Sudeste, e fica abaixo dos $30 \%$ nas outras regiões. É preciso salientar que não é necessário reproduzir o modelo de coleta urbana, mas é urgente realizar avanços na coleta de resíduos domiciliares na área rural.

\section{POLÊM!CA $\mid$ LABORE}

Polêmica - Revista Eletrônica da Uerj - Rua São Francisco Xavier, 524, $1^{\circ}$ andar bloco D, sl.1001 • Tels.: +55 21 2334-4088 / 4087 • http://www.e-publicacoes.uerj.br/index.php/polemica/index http://www.labore.uerj.br • laboreuerj@yahoo.com.br 
O avanço na coleta de resíduos sólidos domiciliares nas áreas urbanas, como aponta a Tabela 1, vem avançando em todas as áreas. No entanto, o que chama atenção é o lento desenvolvimento do processo de coleta nas áreas rurais.

Tabela - 1: Cobertura da coleta direta e indireta de resíduos sólidos (\%) no Brasil e nas Regiões

\begin{tabular}{c|c|c|c}
\hline & 2007 & 2008 & 2009 \\
\hline BRASIL & $\mathbf{8 7 , 3}$ & $\mathbf{8 7 , 9}$ & $\mathbf{8 8 , 6}$ \\
Urbano & $\mathbf{9 7 , 9}$ & $\mathbf{9 8 , 1}$ & $\mathbf{9 8 , 5}$ \\
Rural & $\mathbf{2 8 , 4}$ & $\mathbf{3 0 , 2}$ & $\mathbf{3 2 , 7}$ \\
\hline NORTE & 79,0 & 80,1 & 82,2 \\
Urbano & 95,2 & 95,7 & 97,1 \\
Rural & 23,3 & 24,9 & 29,4 \\
\hline NORDESTE & 73,9 & 75,4 & 76,2 \\
Urbano & 94,3 & 95,3 & 95,8 \\
Rural & 16,9 & 18,4 & 19,8 \\
\hline SUDESTE & 95,3 & 95,3 & 95,9 \\
Urbano & 99,3 & 99,2 & 99,5 \\
Rural & 44,7 & 47,0 & 50,5 \\
\hline SUL & 90,5 & 90,7 & 91,5 \\
Urbano & 99,4 & 99,4 & 99,6 \\
Rural & 44,2 & 46,2 & 49,0 \\
\hline CENTRO-OESTE & 88,2 & 89,2 & 89,9 \\
Urbano & 98,6 & 98,9 & 98,8 \\
Rural & 21,7 & 21,8 & 26,4 \\
\hline
\end{tabular}

Fonte: elaborada pelo autor a partir de Ipea (2012).

Ao observar a área rural, é visível o avanço no percentual de cobertura, mas também sua lentidão se comparado com as áreas urbanas. Para que esses resíduos das áreas rurais não sejam problema no futuro, é preciso uma evolução mais expressiva na coleta. Afinal, a área rural é a fonte de abastecimento para as áreas urbanas; produz e fornece a maioria dos alimentos. Os resíduos não coletados nessa área podem, eventualmente, acabar contaminando a área urbana também. Pode-se vislumbrar um exemplo nas nascentes dos rios, principais fontes de abastecimento hídrico das áreas urbanas, que se localizam nas regiões rurais. Sua poluição acaba comprometendo a qualidade das águas das áreas urbanas. Sobressai, portanto, a necessidade de progressão de uma gestão integrada de resíduos sólidos na área rural.

Conforme o Ipea (2012), uma iniciativa de programa específico para a coleta nas áreas rurais deveria ser estimulada, pois, assim, será possível minimizar a diferença percebida entre a coleta urbana e a rural, principalmente pela natureza distinta que os domicílios rurais possuem. Dificilmente todos os processos implantados nas áreas urbanas - como, por exemplo, coleta

\section{POLÊM!CA | LABORÊ}

Polêmica - Revista Eletrônica da Uerj - Rua São Francisco Xavier, 524, $1^{\circ}$ andar bloco D, sl.1001 • Tels.: +55 21 2334-4088 / 4087 • http://www.e-publicacoes.uerj.br/index.php/polemica/index http://www.labore.uerj.br • laboreuerj@yahoo.com.br 
seletiva e conteinerização - serão replicáveis para a área rural. Isso reforça a necessidade de um modelo diferenciado de gestão de resíduos domiciliares para as áreas rurais, especialmente pela dificuldade de acessibilidade às residências, precariedades das rodovias interioranas e complexidade logística de atender as grandes áreas e extensões sem habitação.

Deve-se orientar em tais localidades para a realização de compostagem de resíduos orgânicos, para não ser coletado e misturado junto, como também a separação dos resíduos recicláveis dos rejeitos, que possuem destinos finais diferentes. Já os resíduos perigosos, as embalagens de agrotóxicos e os restos de produtos químicos concentrados não devem ser enviados por esse tipo de coleta, mas sim devolvidos aos locais de aquisição, de acordo com a logística reversa.

\section{O gerenciamento dos resíduos domiciliares da área rural em Santa Cruz do Sul - RS}

Segundo o PMGIRS-SCS (2013), o Município de Santa Cruz do Sul possui uma área de $794,49 \mathrm{~km}^{2}$, sendo $156,96 \mathrm{~km}^{2}$ de área urbana e $637,53 \mathrm{~km}^{2}$ de área rural. O Plano também relata que o Município possui 118.374 habitantes, sendo 105.184 na área urbana e 13.103 habitantes na área rural, conforme o censo de $2010^{1}$. Deve-se considerar que, de acordo com os censos de 2000 e 2010, a população rural vem diminuindo, conforme a Tabela 2:

Tabela - 2: Concentração da população em Santa Cruz do Sul - RS

\begin{tabular}{c|c|c|c|c}
\hline \multirow{2}{*}{ Censo } & \multirow{2}{*}{ Área Urbana } & \multirow{2}{*}{ Área Rural } & \multicolumn{2}{|c}{ Percentual de aumento/redução } \\
\cline { 5 - 5 } & & & \multirow{2}{*}{ Área Urbana } & \multirow{2}{*}{ Área Rural } \\
\hline 2000 & 93.786 & 13.846 & & $-4,78 \%$ \\
\hline 2010 & 105.190 & 13.184 & $12,16 \%$ & \multirow{2}{*}{} \\
\hline
\end{tabular}

Fonte: elaborada pelo autor a partir de FEE (2013).

Em seu PMGIRS, o município considera que a área rural gera 5,30 toneladas de resíduos por dia, que resultaria em um total de 159 toneladas mês (Tabela 3).

\footnotetext{
${ }^{1}$ Mas, em pesquisa direta no site do IBGE sobre o censo de 2010, foram encontrados 13.184 habitantes na área rural, apresentando, assim, uma diferença de 81 habitantes.
}

\section{POLÊM!CA $\mid$ LABORE}


Tabela - 3: Quantidade de resíduos sólidos gerados na área rural do município de Santa Cruz do Sul, RS

\begin{tabular}{c|c|c}
\hline Ano de Referência & $\begin{array}{c}\text { Quantidade (t/dia) } \\
\text { Área Rural }\end{array}$ & $\begin{array}{c}\text { Quantidade (t/mês) } \\
\text { Área Rural }\end{array}$ \\
\hline 2011 & 2,57 & 77,10 \\
\hline 2012 & 3,59 & 107,70 \\
\hline 2013 & 5,30 & 159,00 \\
\hline
\end{tabular}

Fonte: elaborada pelo autor a partir de PMGIRS-SCS, 2013.

O aumento da quantidade em toneladas geradas nas áreas rurais poderia estar relacionado ao aumento do consumo de embalagens, já que não há indicativo de crescimento populacional local mas sim a facilitação na aquisição de produtos. No entanto, o Diagnóstico dos Resíduos Sólidos Urbanos (IPEA, 2012), aponta, conforme a Tabela 4, um aumento da produção de embalagens cujo percentual não representa grande significância:

Tabela - 4: Aumento da produção de embalagens no Brasil

\begin{tabular}{c|c|c}
\hline Ano & $\begin{array}{c}\text { Índice especial do IBGE para o } \\
\text { segmento de embalagens }\end{array}$ & Percentual de aumento \\
\hline 2010 & 102,90 & - \\
\hline 2011 & 104,31 & $1,35 \%$ \\
\hline 2012 & 102,53 & $-1,74 \%$ \\
\hline 2013 & 103,29 & $0,74 \%$ \\
\hline
\end{tabular}

Fonte: elaborada pelo autor a partir do IPEA (2012).

Outro ponto que se deve destacar, como aponta o censo de 2010 do IBGE, é que ainda existe a prática de queimar e enterrar resíduos domiciliares nas propriedades rurais. Essa prática se espalha pelo país inteiro, incluindo registros em Santa Cruz do Sul. Existem dados coletados por meio das entrevistas do censo que demonstram que uma parcela dos resíduos rurais do município ainda é manejada pelos habitantes dessa forma, sendo a queima e o enterramento seu eventual destino (Tabela 5).

\section{POLÊM!CA | LABORÉ}

Polêmica - Revista Eletrônica da Uerj - Rua São Francisco Xavier, 524, $1^{\circ}$ andar bloco D, sl.1001 • Tels.: +55 21 2334-4088 / 4087 • http://www.e-publicacoes.uerj.br/index.php/polemica/index http://www.labore.uerj.br • laboreuerj@yahoo.com.br 
Tabela - 5: Destino dos resíduos domiciliares em propriedades rurais

\begin{tabular}{|c|c|c|}
\hline \multirow{2}{*}{$\begin{array}{c}\text { Brasil - Unidade da Federação - } \\
\text { Município }\end{array}$} & \multicolumn{2}{|c|}{ Destino do lixo (toneladas por ano) } \\
\hline & $\begin{array}{l}\text { Queimado (na } \\
\text { propriedade) }\end{array}$ & $\begin{array}{l}\text { Enterrado (na } \\
\text { propriedade) }\end{array}$ \\
\hline Brasil & 4.702 .758 & 293.324 \\
\hline Rio Grande do Sul & 187.061 & 31.223 \\
\hline Santa Cruz do Sul & 496 & 45 \\
\hline
\end{tabular}

Fonte: elaborada pelo autor a partir de IBGE (2010).

Apesar de ser um volume muito baixo se comparado aos números do Rio Grande do Sul e do Brasil, eles representam um número significativo para um município que possui um baixo percentual de população na área rural - 11,08\%, conforme o PMGIRS-SCS (2013).

Para Pedroso (2010), a coleta de lixo na área rural ainda é insuficiente, pois não atinge todos os domicílios brasileiros. Em 1991, do total de lixo produzido na zona rural, 31,6\% eram enterrados ou queimados. Esse percentual subiu para 52,5\% em 2000 (DAROLT, 2008). A realidade mostra que o lixo rural tem coleta cara e difícil, o que leva os agricultores a optarem por enterrá-lo ou queimá-lo (IBGE, 2010), perpetuando tais práticas até o presente. Esse cenário demonstra a dificuldade de uma boa gestão dos resíduos rurais, fazendo com que proprietários optem pela alternativa mais simples de destinação de resíduos.

Mesmo com esses dados - população rural abaixo da média e de manejo inadequado , cabe salientar que a Prefeitura de Santa Cruz do Sul mantém um contrato com uma empresa privada para a coleta do resíduo rural. Segundo os dados do PMGIRS, o custo da coleta está demonstrado na Tabela 6:

Tabela - 6: Custo anual gasto com a coleta de resíduos na área rural do município de Santa Cruz do Sul, RS

\begin{tabular}{c|c|c|c|c}
\hline Ano de Referência & Quantidade (km/mês) & Quantidade $(\mathrm{km} / \mathrm{ano})$ & $\begin{array}{c}\text { Custo por km } \\
(\mathrm{R} \$ / \mathrm{km})\end{array}$ & $\begin{array}{c}\text { Custo com coleta } \\
(\mathrm{R} \$ / \mathrm{ano})\end{array}$ \\
\hline 2011 & $5.198,42$ & $62.381,04$ & 2,68 & $167.337,14$ \\
\hline 2012 & $5.705,38$ & $68.464,56$ & 2,82 & $193.015,29$ \\
\hline 2013 (até outubro) & $5.634,08$ & $56.340,80$ & 3,04 & $171.276,03$ \\
\hline
\end{tabular}

Fonte: elaborada pelo autor a partir de PMGIRS-SCS (2013).

Pelo PMGIRS-SCS (2013), o último valor completo que pode servir de base é do ano de 2012. Mas, durante uma reunião do Fórum de Ação pela Coleta Seletiva - FACS, realizada no Parque da Oktoberfest, no dia 07/07/2015, foi disponibilizado o valor mais atualizado gasto

\section{POLÊM!CA $\mid$ LABORE}

Polêmica - Revista Eletrônica da Uerj - Rua São Francisco Xavier, 524, $1^{\circ}$ andar bloco D, sl.1001 • Tels.: +55 21 2334-4088 / 4087 • http://www.e-publicacoes.uerj.br/index.php/polemica/index http://www.labore.uerj.br • laboreuerj@yahoo.com.br 
pelo município na coleta de resíduos da área rural, equivalente a $R \$ 5,45$ por quilômetro rodado. Identificou-se também o valor do Edital de Concorrência No 40/07. Dessa forma, elaborou-se a Tabela 7 para apresentar todos esses dados em sequência.

Tabela - 7: Custo anual gasto com a coleta de resíduos na área rural, com novos dados

\begin{tabular}{|c|c|c|c|c|c|}
\hline $\begin{array}{l}\text { Ano de } \\
\text { Referência }\end{array}$ & $\begin{array}{l}\text { Quantidade } \\
\text { (km/mês) }\end{array}$ & $\begin{array}{l}\text { Quantidade } \\
\text { (km/ano) }\end{array}$ & $\begin{array}{l}\text { Custo por km } \\
\qquad(\mathrm{R} \$ / \mathrm{km})\end{array}$ & $\begin{array}{l}\text { Custo com coleta } \\
\text { (R\$/ano) }\end{array}$ & Fonte: \\
\hline 2007 & $5.207,00$ & $62.484,00$ & 2,1221 & $\mathrm{R} \$ 132.597,30$ & $\begin{array}{c}\text { Edital de Concorrência } \mathrm{N}^{\circ} \\
40 / 07\end{array}$ \\
\hline 2011 & $5.198,42$ & $62.381,04$ & 2,68 & $\mathrm{R} \$ 167.337,14$ & \multirow{3}{*}{ PMGIRS - SCS (2013) } \\
\hline 2012 & $5.705,38$ & $68.464,56$ & 2,82 & $\mathrm{R} \$ 193.015,29$ & \\
\hline $\begin{array}{l}2013 \text { (até } \\
\text { outubro) }\end{array}$ & $5.634,08$ & $56.340,80$ & 3,04 & $\mathrm{R} \$ 171.276,03$ & \\
\hline 2015 & $5.634,08$ & $67.608,96$ & 5,45 & $\mathrm{R} \$ 368.468,83$ & $\begin{array}{c}\text { Avaliação das Metas e } \\
\text { Ações do PMGIRS de } \\
\text { Santa Cruz do Sul-RS } \\
\text { Encontro Geral do FACS - } \\
07 / 07 / 2015\end{array}$ \\
\hline
\end{tabular}

Fonte: elaborada pelo autor a partir do Edital de Concorrência n ${ }^{\circ}$ 40/7 (SANTA CRUZ DO SUL, 2007), PMGIRSSCS (SANTA CRUZ DO SUL, 2013) e Avaliação das Metas e Ações do PMGIRS de Santa Cruz do Sul-RS (SANTA CRUZ DO SUL, 2015).

A partir da análise dos três documentos e os dados da Tabela 7, pode-se evidenciar o aumento dos gastos nesse processo. Mesmo que, para o ano de 2015, o único valor que a Prefeitura Municipal disponibilizou em sua apresentação tenha sido o custo por $\mathrm{km}(\mathrm{R} \$ / \mathrm{km})$, utilizou-se a média de quilômetros por mês de 2013, que estava um pouco mais baixa que a média de 2012.

$\mathrm{Na}$ Tabela 8, os dados representam o real aumento na coleta regular de resíduos sólidos na área rural, bem como o valor mensal da coleta de resíduos sólidos nas áreas rurais, junto com o respectivo percentual de variação. Além disso, incluiu-se o valor pago pela coleta por cada morador que vive nessas áreas.

Tabela - 8: Custo mensal e por habitante com a coleta de resíduos da área rural

\begin{tabular}{c|c|c|c|c|c|c}
\hline Ano & $\begin{array}{c}\text { Quantidade } \\
(\mathrm{km} / \mathrm{mês})\end{array}$ & $\begin{array}{c}\text { Custo por } \\
\mathrm{km} \\
(\mathrm{R} \$ / \mathrm{km})\end{array}$ & $\begin{array}{c}\text { Custo com a } \\
\text { coleta } \\
(\mathrm{R} \$ / \mathrm{mês})\end{array}$ & $\begin{array}{c}\text { População } \\
\text { área rural }\end{array}$ & $\begin{array}{c}\text { Custo da coleta anual } \\
\text { por habitante na área } \\
\text { rural }(\mathrm{R} \$ / \mathrm{ano} / \mathrm{hab})\end{array}$ & $\begin{array}{c}\text { Percentual de } \\
\text { aumento }(\%)\end{array}$ \\
\hline 2007 & $5.207,00$ & 2,1221 & $\mathrm{R} \$ 11.049,77$ & 13.846 & $\mathrm{R} \$ 9,58$ & - \\
\hline 2011 & $5.198,42$ & 2,68 & $\mathrm{R} \$ 13.931,77$ & 13.184 & $\mathrm{R} \$ 12,68$ & $24,48 \%$ \\
\hline 2012 & $5.705,38$ & 2,82 & $\mathrm{R} \$ 16.089,17$ & 13.184 & $\mathrm{R} \$ 14,64$ & $13,41 \%$ \\
\hline $\begin{array}{c}2013 \\
\text { projeção) }\end{array}$ & $5.634,08$ & 3,04 & $\mathrm{R} \$ 17.127,60$ & 13.184 & $\mathrm{R} \$ 15,59$ & $6,06 \%$ \\
\hline 2015 & $5.634,08$ & 5,45 & $\mathrm{R} \$ 30.705,74$ & 13.184 & $\mathrm{R} \$ 27,95$ & $44,22 \%$ \\
\hline
\end{tabular}

\section{POLÊM!CA | LABORË}

Polêmica - Revista Eletrônica da Uerj - Rua São Francisco Xavier, 524, $1^{\circ}$ andar bloco D, sl.1001 • Tels.: +55 21 2334-4088 / 4087 • http://www.e-publicacoes.uerj.br/index.php/polemica/index http://www.labore.uerj.br • laboreuerj@yahoo.com.br 
Fonte: elaborada pelo autor a partir do Edital de Concorrência n ${ }^{\circ} 40 / 7$ (SANTA CRUZ DO SUL, 2007), PMGIRSSCS (SANTA CRUZ DO SUL, 2013), Avaliação das Metas e Ações do PMGIRS de Santa Cruz do Sul-RS (SANTA CRUZ DO SUL, 2015) e FEE (2013).

A partir da percepção de aumento de custo entre 2013 e 2015, haveria a necessidade de verificar se ocorreu algum acréscimo nas distâncias percorridas na coleta de resíduos domiciliares da área rural. No entanto, não há dados de 2015 disponíveis para uma melhor avaliação. Considerando tal ausência, propõe-se aqui comparar as distâncias que constam no Edital de Concorrência 40/07 e no PMGIRS-SCS (2013), conforme os Quadros 1 e 2, para verificação do histórico.

Quadro - 1: Distâncias percorridas nas áreas rurais - Edital de Concorrência 40/07

\begin{tabular}{|c|c|c|c|c|}
\hline SETOR & LOCALIDADES & DISTÂNCIA & FREQUÊNCIA & PERÍODO \\
\hline $\begin{array}{c}\text { Setor } \\
01\end{array}$ & $\begin{array}{c}\text { Rio Pardinho, Corredor Goerck, Balneário Scherer, } \\
\text { Travessa Andreas, Travessa Dona Josefa, Entrada } \\
\text { Panke, Balneário Panke, Ponte Rio Pardinho, Linha } \\
\text { Sete de Setembro (até o Balneário) e Linha } \\
\text { Travessa } \\
\end{array}$ & $126 \mathrm{~km}$. & $\begin{array}{l}02 \text { (duas) vezes } \\
\text { por semana }\end{array}$ & Diurno \\
\hline $\begin{array}{c}\text { Setor } \\
02\end{array}$ & $\begin{array}{c}\text { São Martinho, Paredão, Linha do Moinho, Alto Boa } \\
\text { Vista, Linha Felipe Nery }\end{array}$ & $200 \mathrm{~km}$. & $\begin{array}{l}03 \text { (três) vezes } \\
\text { por }\end{array}$ & Diurno \\
\hline $\begin{array}{c}\text { Setor } \\
03\end{array}$ & $\begin{array}{c}\text { Linha Eugênia, Linha Araçá, Quarta Linha Alta, } \\
\text { Quarta Linha Nova Baixa, Entrada Andrade Neves, } \\
\text { Linha General Osório }\end{array}$ & $158 \mathrm{~km}$. & $\begin{array}{l}03 \text { (três) vezes } \\
\text { por mês }\end{array}$ & Diurno \\
\hline $\begin{array}{c}\text { Setor } \\
04\end{array}$ & $\begin{array}{c}\text { Linha Chaves, Alto Boa Vista, Arroio do Tigre, } \\
\text { Linha Botão, Linha Vitorino Monteiro, Picada da } \\
\text { Mula, Cerro dos Cabritos, Arroio do Leite }\end{array}$ & $169 \mathrm{~km}$. & $\begin{array}{l}03 \text { (três) vezes } \\
\text { por mês }\end{array}$ & Diurno \\
\hline $\begin{array}{l}\text { Setor } \\
05\end{array}$ & $\begin{array}{c}\text { Linha Sete de Setembro, Cerro Alegre Alto, Linha } \\
\text { Áustria (parte) }\end{array}$ & $117 \mathrm{~km}$. & $\begin{array}{l}03 \text { (três) vezes } \\
\text { por mês }\end{array}$ & Diurno \\
\hline $\begin{array}{l}\text { Setor } \\
06\end{array}$ & $\begin{array}{c}\text { Monte Alverne, Boa Vista, Pinheiral, Seival, Linha } \\
\text { João Alves, Linha Nova, Linha Chaves, Linha } \\
\text { Monte Alverne, Linha Andrade Neves (parte) }\end{array}$ & $231 \mathrm{~km}$. & $\begin{array}{l}02 \text { (duas) vezes } \\
\text { por semana }\end{array}$ & Diurno \\
\hline $\begin{array}{l}\text { Setor } \\
07\end{array}$ & $\begin{array}{l}\text { Cerro Alegre, Parque de Eventos, Reserva dos } \\
\text { Kroth, Recanto do Laço e Autódromo }\end{array}$ & $113 \mathrm{~km}$. & $\begin{array}{l}03 \text { (três) vezes } \\
\text { por mês }\end{array}$ & Diurno \\
\hline
\end{tabular}

Fonte: elaborada pelo autor a partir do Edital de Concorrência nº 40/07 (SANTA CRUZ DO SUL, 2007).

\section{POLÊM!CA $\mid$ LABORE}

Polêmica - Revista Eletrônica da Uerj - Rua São Francisco Xavier, 524, $1^{\circ}$ andar bloco D, sl.1001 • Tels.: +55 21 2334-4088 / 4087 • http://www.e-publicacoes.uerj.br/index.php/polemica/index http://www.labore.uerj.br • laboreuerj@yahoo.com.br 
Quadro - 2: Rotas nas áreas rurais - PMGIRS-SCS, 2013

\begin{tabular}{|c|c|c|c|}
\hline SETOR & LOCALIDADES & FREQUENCIA & PERÍODO \\
\hline $\begin{array}{c}\text { Setor } \\
01\end{array}$ & $\begin{array}{c}\text { Rio Pardinho, Corredor Goerck, Balneário Scherer, Travessa Andreas, } \\
\text { Travessa Dona Josefa, Entrada Panke, Balneário Panke, Ponte Rio } \\
\text { Pardinho, Linha Sete de Setembro (até o Balneário) e Linha Travessa }\end{array}$ & $\begin{array}{c}\text { 02 (duas) vezes } \\
\text { por semana }\end{array}$ & Diurno \\
\hline $\begin{array}{c}\text { Setor } \\
02\end{array}$ & $\begin{array}{c}\text { São Martinho, Paredão, Linha do Moinho, Alto Boa Vista, Linha Felipe } \\
\text { Nery }\end{array}$ & $\begin{array}{c}\text { 03 (três) vezes } \\
\text { por }\end{array}$ & Diurno \\
\hline $\begin{array}{c}\text { Setor } \\
03\end{array}$ & $\begin{array}{c}\text { Linha Eugênia, Linha Araçá, Quarta Linha Alta, Quarta Linha Nova } \\
\text { Baixa, Entrada General Osório }\end{array}$ & $\begin{array}{c}\text { 03 (três) vezes } \\
\text { por mês }\end{array}$ & Diurno \\
\hline $\begin{array}{c}\text { Setor } \\
04\end{array}$ & $\begin{array}{c}\text { Linha Chaves, Alto Boa Vista, Arroio do Tigre, Linha Botão, Linha } \\
\text { Vitorino Monteiro, Picada da Mula, Cerro dos Cabritos, Arroio do } \\
\text { Leite }\end{array}$ & $\begin{array}{c}\text { 03 (três) vezes } \\
\text { por mês }\end{array}$ & Diurno \\
\hline $\begin{array}{c}\text { Setor } \\
05\end{array}$ & Linha Sete de Setembro, Cerro Alegre Alto, Linha Áustria (parte) & $\begin{array}{c}\text { 03 (três) vezes } \\
\text { por mês }\end{array}$ & Diurno \\
\hline $\begin{array}{c}\text { Setor } \\
06\end{array}$ & $\begin{array}{c}\text { Monte Alverne, Boa Vista, Pinheiral, Seival, Linha João Alves, Linha } \\
\text { Nova, Linha Chaves, Linha Monte Alverne, Linha Andrade Neves } \\
\text { (parte) }\end{array}$ & $\begin{array}{c}\text { 02 (duas) vezes } \\
\text { por semana }\end{array}$ & Diurno \\
\hline $\begin{array}{c}\text { Setor } \\
07\end{array}$ & $\begin{array}{c}\text { Cerro Alegre, Parque de Eventos, Reserva dos Kroth, Recanto do Laço } \\
\text { e Autódromo }\end{array}$ & $\begin{array}{c}\text { 03 (três) vezes } \\
\text { por mês }\end{array}$ & Diurno \\
\hline
\end{tabular}

Fonte: elaborada pelo autor a partir do PMGIRS-SCS (SANTA CRUZ DO SUL, 2013).

A partir da análise desses dois quadros, pode-se perceber que as rotas rurais apresentam uma semelhança, ou seja, parece que a coleta e seus trajetos já estão solidificados nas áreas rurais. Apenas no Setor 03, apresenta-se uma diferença, mas que parece apenas uma falha de digitação. No Quadro 2, que foi disponibilizado no PMGIRS-SCS (2013), não há a coluna "distância", que determinava o intervalo percorrido nas áreas rurais e era a base para fazer o cálculo de pagamento, já que a contratação se dá pelo valor do quilômetro rodado.

Após essa apuração de dados, pode-se tentar determinar a quantidade de quilometragem média de cada carga, como também a quantidade média de toneladas que chegam em cada carga (Tabela 9):

Tabela - 9: Quantidade média de quilômetros e peso por carga de resíduos da área rural do município de Santa Cruz do Sul, RS

\begin{tabular}{c|c|c|c|c}
\hline $\begin{array}{c}\text { Quantidade } \\
(\mathrm{km} / \mathrm{mês})\end{array}$ & $\begin{array}{c}\text { Quantidade } \\
\text { (t/mês) } \\
\text { conforme } \\
\text { Tabela 6 Rural, } \\
\text { conforme } \\
\text { Tabela 3 }\end{array}$ & $\begin{array}{c}\text { Média de } \\
\text { Cargas } \\
\text { mensais nas } \\
\text { áreas rurais } \\
\text { conforme } \\
\text { Quadro 2 }\end{array}$ & $\begin{array}{c}\text { Quilometragem } \\
\text { média por } \\
\text { carga }\end{array}$ & $\begin{array}{c}\text { Toneladas } \\
\text { transportadas por } \\
\text { cargas }\end{array}$ \\
\hline $5.634,08$ & 159,00 & 31,00 & 181,74 & 5,13 \\
\hline
\end{tabular}

Fonte: elaborada pelo autor a partir do PMGIRS-SCS (SANTA CRUZ DO SUL, 2013).

\section{POLÊM!CA $\mid$ LABORE}

Polêmica - Revista Eletrônica da Uerj - Rua São Francisco Xavier, 524, $1^{\circ}$ andar bloco D, sl.1001 • Tels.: +55 21 2334-4088 / 4087 • http://www.e-publicacoes.uerj.br/index.php/polemica/index http://www.labore.uerj.br • laboreuerj@yahoo.com.br 
Depois dos resíduos domiciliares das áreas rurais serem coletados, eles são levados para a Usina de Triagem de Santa Cruz do Sul, que é administrada pela COOMCAT. Todo caminhão que recolhe o resíduo domiciliar urbano informa o peso transportado na portaria, mas os caminhões que transportam o resíduo domiciliar da área rural não disponibilizam o peso transportado. Por isso, a média calculada na Tabela 9 irá ajudar com a reflexão. Perguntado a um técnico da prefeitura, a informação foi de que apenas 60 toneladas por mês de resíduos domésticos eram geradas nas áreas rurais, diferindo do que está no PMGIRS-SCS (2013), que aponta 159 toneladas diárias em 2013. Nesse sentido, fez-se um levantamento de entrada de cargas na Usina de Triagem fixando uma análise sobre o mês de agosto de 2013, 2014 e 2015. Utilizando as 159 toneladas mensais encontradas na Tabela 3, elaborou-se a Tabela 10:

Tabela - 10: Comparativo de entrada cargas na Usina de Triagem com os dados PMGIRS-SCS

\begin{tabular}{c|c|c|c|c|c|c}
\hline Mês & Ano & $\begin{array}{c}\text { Quantidade } \\
\text { de cargas } \\
\text { recebida na } \\
\text { Usina de } \\
\text { Triagem }\end{array}$ & $\begin{array}{c}\text { Média de } \\
\text { Cargas nas } \\
\text { àreas rurais } \\
\text { conforme } \\
\text { Quadro 2 }\end{array}$ & $\begin{array}{c}\text { Aumento } \\
\text { na } \\
\text { quantidade } \\
\text { de cargas } \\
(\%)\end{array}$ & $\begin{array}{c}\text { Quilometragem } \\
\text { média realizada por } \\
\text { mês, baseado nos } \\
181,74 \mathrm{~km} \text { da Tabela } \\
9\end{array}$ & $\begin{array}{c}\text { Toneladas } \\
\text { transportadas por } \\
\text { cargas, baseado nas } \\
159 \text { toneladas } \\
\text { mensais }\end{array}$ \\
\hline Agosto & 2013 & 29 & 31 & $-6,45$ & $5.270,46$ & 5,48 \\
\hline Agosto & 2014 & 33 & 31 & 6,45 & $5.997,42$ & 4,82 \\
\hline Agosto & 2015 & 44 & 31 & 41,94 & $7.996,56$ & 3,61 \\
\hline
\end{tabular}

Fonte: elaborada pelo autor a partir de dados da portaria da Usina de Triagem de 2013, 2014, 2015 e PMGIRSSCS (SANTA CRUZ DO SUL, 2013).

De acordo com a coluna frequência do Quadro 2, pode-se determinar a quantidade de cargas que deveriam vir das áreas rurais, que, no caso, dentro de um mês ficariam em torno de 31 cargas. Percebe-se que, conforme os registros de entradas das cargas dos meses de agosto de 2013, 2014 e 2015, as quantidades de cargas nas áreas rurais estão aumentando. Aliado a isso, as quantidades de cargas foram divididas pelos valores de peso disponibilizados no PMGIRS-SCS (2013) e de quilometragem calculados na Tabela 9 e, consequentemente, o peso transportado vem diminuindo, mas a quilometragem mensal, baseada na média, vem aumentando.

Outro ponto a salientar é que o resíduo das áreas rurais é muito esperado pelos catadores, pois, em sua composição, a maior parte é reciclável, sendo muito importante economicamente para a sua atividade. As figuras 1, 2, 3 e 4 são fotos da Usina de Triagem. Foi acompanhada a chegada e o descarregamento de um caminhão compactador, que realizava a rota e a coleta de

\section{POLÊM!CA $\mid$ LABORE}

Polêmica - Revista Eletrônica da Uerj - Rua São Francisco Xavier, 524, $1^{\circ}$ andar bloco D, sl.1001 • Tels.: +55 21 2334-4088 / 4087 • http://www.e-publicacoes.uerj.br/index.php/polemica/index http://www.labore.uerj.br • laboreuerj@yahoo.com.br 
resíduos sólidos domiciliares das áreas rurais de Santa Cruz do Sul, evidenciando a quantidade de material reciclável presente nas cargas.

Figura - 1: Caminhão compactador descarregando

Fonte: acervo do autor (2015).

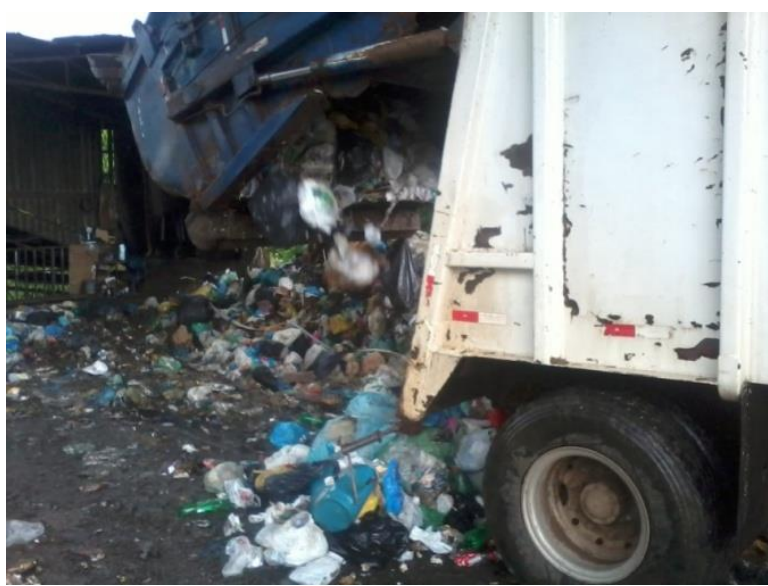

Figura - 2: Resíduo saindo do caminhão compactador, incluindo materiais recicláveis

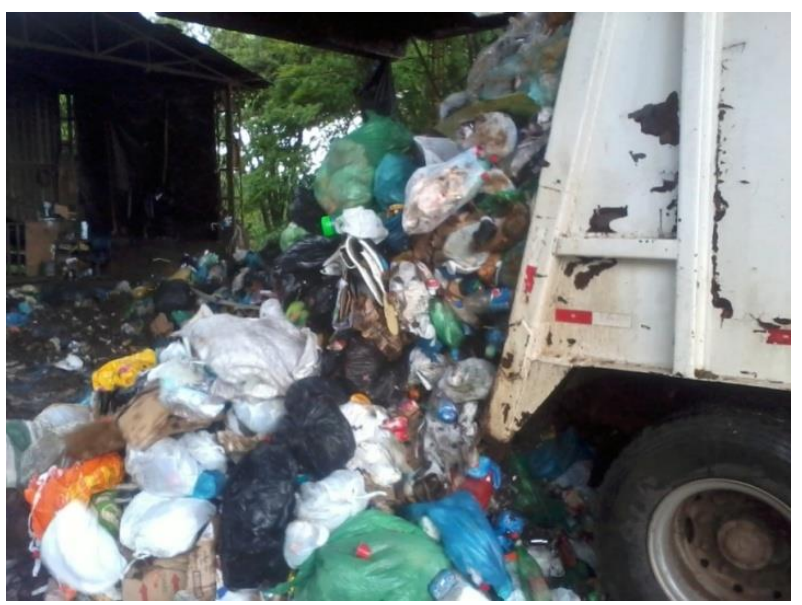

Fonte: acervo do autor (2015).

\section{POLÊM!CA | LABORE (}


Figura - 3: Resíduo disposto na área de transbordo

Fonte: acervo do autor (2015).

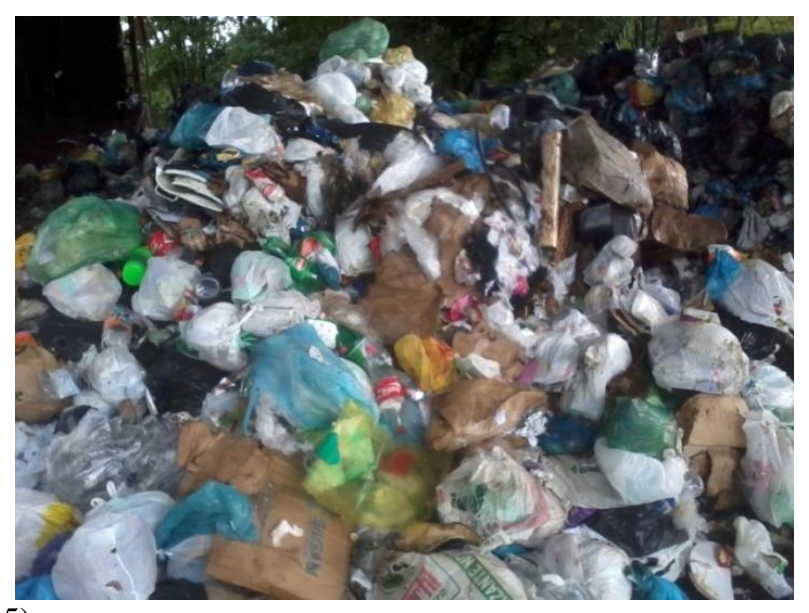

Figura - 4: Caminhão descarregado, saindo da Usina

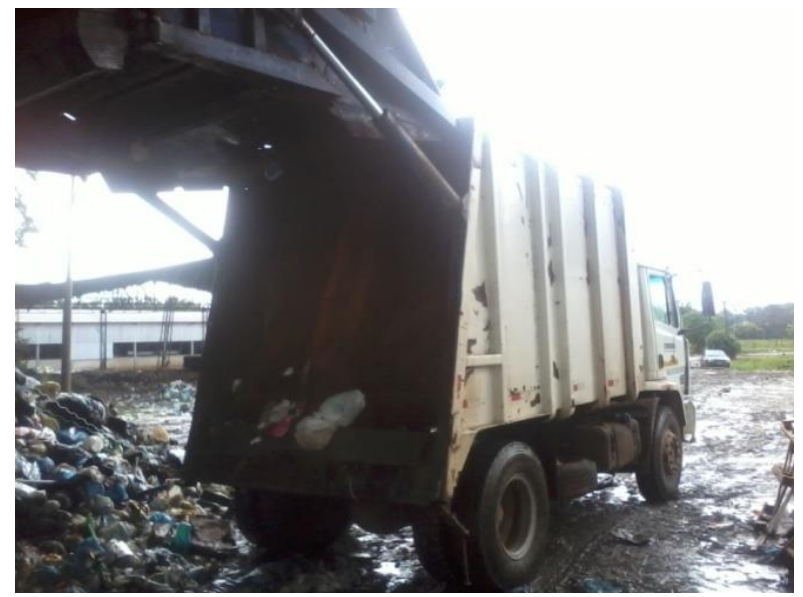

Fonte: acervo do autor (2015).

Por meio das imagens, pode-se observar como é realizada a coleta, o transporte e a destinação dos resíduos sólidos domésticos das áreas rurais de Santa Cruz do Sul na Usina de Triagem. Na portaria, o caminhão, ao ser recebido, tem sua placa, rota, motorista e o horário anotados e na sequência dão destino a carga. Ela pode ser destinada para a Triagem, ou diretamente para o Transbordo. Segundo a pesquisa documental, as cargas que vem das áreas rurais são destinadas para a Triagem na sua totalidade, pois concentram mais materiais recicláveis que as outras cargas que acessam a Usina de Triagem.

Embora ocorra o descarte dos resíduos sólidos rurais nas usinas de reciclagem, Soares et al. (2013) destaca que alguns resíduos domiciliares ainda são dispostos nos quintais, e que existem relatos de sufocamento e morte de animais pela ingestão de sacos plásticos, além da diminuição de peixes pela poluição das águas, principalmente por causa dos períodos de chuva

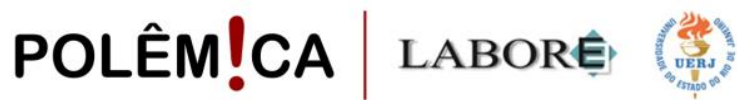

Polêmica - Revista Eletrônica da Uerj - Rua São Francisco Xavier, 524, $1^{\circ}$ andar

bloco D, sl.1001 • Tels.: +55 21 2334-4088 / 4087 • http://www.e-publicacoes.uerj.br/index.php/polemica/index http://www.labore.uerj.br • laboreuerj@yahoo.com.br 
que arrastam todos os tipos de resíduos para dentro dos rios e açudes. Segundo Darolt (2008), essa despreocupação social com o resíduo gerado na área rural vem de uma ideia errada de considerar reduzido o número de habitantes na área rural. Porém, não se tem a percepção que os danos ambientais locais terão reflexos importantes na qualidade de vida das áreas urbanas, principalmente em se tratando da água que é fornecida para as cidades.

\section{Resultados e discussões}

Com base nos dados apresentados foi possível constatar uma contradição, principalmente pela forma como o plano apresenta os dados, considerando a quantidade de cargas recebidas (31 por mês). Evidenciou-se que o aumento de embalagens não é muito significativo, portanto, não poderia estar causando esse crescimento. O motivo do aumento de cargas em $42 \%$ ocorre pela vantagem de se cobrar por quilometragem, e não possuir uma forma de verificar quantidade, em toneladas, de resíduos, que cada carga de coleta de resíduo doméstico rural transportada indicaria.

Mas mesmo com essa problemática exposta e, a partir dos dados apresentados, pôde-se perceber que a coleta no meio rural está a cada ano avançando. Mesmo em um país com uma grande área territorial como o Brasil, vem-se buscando alternativas e aumentando a quantidade recolhida. Apesar do alto custo, os municípios, principalmente da Região Sul e Sudeste, já perceberam que a população rural deve ser atendida.

Outro ponto que se deve observar é que o censo do IBGE (2010) aponta para uma diminuição da população das áreas rurais no município de Santa Cruz do Sul${ }^{2}$. Dessa forma, ter-se-ia que observar a diminuição do resíduo domiciliar nas áreas rurais, o que, como indica a pesquisa, não ocorreu. Por outro lado, percebe-se que nos últimos anos, essa população possui o mesmo acesso aos produtos da área urbana. Isso poderia ter incrementado a geração de resíduos domésticos nas áreas rurais nos últimos anos, mas, como já dito, os dados do IPEA (2012) informam que não há um aumento considerável na produção de embalagens, o que não poderia resultar nesse volume de cargas mais alto nas áreas rurais.

Observou-se que as localidades, a frequência e o período de coleta até 2013 não haviam sido alterados, apenas retirada a coluna que delimitava a quilometragem percorrida, ou seja,

\footnotetext{
${ }^{2}$ É importante ressaltar que um dado populacional mais atual não foi disponibilizado ainda devido ao atraso na realização do Censo, anteriormente previsto para 2020.
}

\section{POLÊM!CA $\mid$ LABORE}

Polêmica - Revista Eletrônica da Uerj - Rua São Francisco Xavier, 524, $1^{\circ}$ andar bloco D, sl.1001 • Tels.: +55 21 2334-4088 / 4087 • http://www.e-publicacoes.uerj.br/index.php/polemica/index http://www.labore.uerj.br • laboreuerj@yahoo.com.br 
não existe nenhuma informação sobre aumento das distâncias nas coletas das áreas rurais. A retirada dos valores referentes à distância do Edital de Concorrência 40/07 para o PMGIRSSCS (2013) representa uma dificuldade de acesso à informação e a falta de transparência na utilização do dinheiro público para pagar os serviços.

Observa-se uma contradição, quando o PMGIRS-SCS (2013) aponta um aumento considerável na quantidade de resíduos gerados nas áreas rurais (em 2011 eram geradas 77,10 toneladas, em 2013 passou para 159,00). Mesmo se levássemos em conta os dados do IBGE (2010), sobre o resíduo queimado e enterrado, essa realidade de 2011 representaria 122,18 toneladas/mês, não chegando perto do aumento descrito entre 2011 e 2013. Mas a dúvida persiste quando se observa que não existe aumento da população nas áreas rurais, nem ampliação das áreas através das distâncias e nem pesagem das cargas de resíduos sólidos domésticos das áreas rurais. Como então, consideram esses valores?

Essas cargas, por não serem pesadas, podem gerar oscilações, como evidenciado nos registros do número de cargas que chegam na portaria da Usina de Triagem. Dessa forma, foi possível verificar que um aumento na quantidade do número de cargas, mesmo que definido no PMGIRS-SCS (2013), irá configurar, com certeza, um aumento na quilometragem relativa à coleta desses resíduos.

O contrato de coleta de resíduos sólidos estipula que a cobrança é por quilometragem, não por número de cargas e nem por quantidade de resíduos, porém, de 2013 para 2015, aumentou em quase 41,94\%, e os dados de distâncias foram suprimidos do PMGIRS-SCS. Mesmo que exista um aumento real na geração de resíduos nas áreas rurais nos últimos anos, os dados apresentados não revelam esta situação, e desta forma, não foi possível verificar o quanto está sendo pago por mês pela coleta de resíduos nas áreas rurais pela Prefeitura de Santa Cruz do Sul.

\section{Considerações finais}

É importante considerar a adoção de uma gestão integrada de resíduos sólidos, disponibilizando os dados de maneira transparente e com livre acesso a quem possa interessar, a fim de verificar a dinâmica dos dados de forma clara e inteligível pela população. A divergência expressiva encontrada entre os valores medidos nos anos de 2013 e 2015, poderia ser esclarecida se fossem pesadas as cargas originárias das áreas rurais, o que não era feito até

\section{POLÊM!CA $\mid$ LABORE}

Polêmica - Revista Eletrônica da Uerj - Rua São Francisco Xavier, 524, $1^{\circ}$ andar bloco D, sl.1001 • Tels.: +55 21 2334-4088 / 4087 • http://www.e-publicacoes.uerj.br/index.php/polemica/index http://www.labore.uerj.br • laboreuerj@yahoo.com.br 
o final do ano de 2015. Caso as cargas tivessem sido pesadas poderiam ter sinalizado mais claramente algum problema para os gestores municipais realizarem a correção durante o processo ou para a população exigir a explicação dos fatos, já que a gestão desses processos é realizada com o dinheiro dos impostos da população, devendo ser o mais transparente possível, eliminando dúvidas.

Outra reflexão que se deve fazer dentro dessa pesquisa é que vem aumentando o número de cargas e o equipamento que realiza essa tarefa (caminhão compactador) poderia não ser adequado para transportar o volume necessário. Se a capacidade de carga fosse maior, poderia fazer todo o roteiro carregando mais resíduo.

Relevante ainda é a questão da contaminação que ocorre nas áreas rurais por má adequação dos resíduos sólidos. Isso trará um prejuízo significativo para todos. A água que se consome vem das nascentes localizadas nas áreas rurais, assim como nosso alimento, por isso os municípios devem investir em boas gestões de resíduos rurais, para evitarem problemas de contaminação do solo, afetando a produção de alimentos, bem como contaminando as águas. No entanto, é preciso observar com atenção o preço pago por esse serviço, pois este custo poderá ser elevado para o município, implicando na redução do investimento em outros serviços básicos.

A criação de novos hábitos pode contribuir para a construção de uma sociedade mais consciente, informada, atenta e comprometida (ROCHA, 2012). Destinando e tratando os resíduos de forma adequada, a probabilidade de impactos ambientais diminuirá, consequentemente, os desastres ambientais também. Por esse motivo, deve-se estimular a coleta seletiva, aproveitar a disposição dos habitantes das áreas rurais, além de cobrar políticas públicas eficientes. Pesquisas como essa podem estimular a reflexão e o investimento em gestões qualificadas de resíduos - tão importante na atualidade -, bem como a transparência em seus processos.

\section{Referências}

BARBOSA, George Leandro Monte. Gerenciamento de Resíduo Sólido: Assentamento Sumaré II. 2005. Dissertação (Mestrado em Saneamento e Ambiente) - Faculdade de Engenharia Civil, Arquitetura e Urbanismo, Universidade Estadual de Campinas, Campinas, 2005. Disponível em: http://www.bvssp.icict.fiocruz.br/lildbi/docsonline/get.php?id=5>1. Acesso em: 24 mar. 2017.

\section{POLÊM!CA $\mid$ LABORE}

Polêmica - Revista Eletrônica da Uerj - Rua São Francisco Xavier, 524, $1^{\circ}$ andar bloco D, sl.1001 • Tels.: +55 21 2334-4088 / 4087 • http://www.e-publicacoes.uerj.br/index.php/polemica/index http://www.labore.uerj.br • laboreuerj@yahoo.com.br 
BRASIL. Lei nº 12.305. Institui a Política Nacional dos Resíduos Sólidos; altera a Lei 9.605, de fevereiro de 1998; e dá outras providencias. Diário Oficial da União, Brasília, DF, 2 ago. 2010. Seção 1, p. 3. Disponível em: http://www.planalto.gov.br/ccivil_03/_ato2007-2010/2010/lei/112305.htm. Acesso em: 14 fev. 2017.

DAROLT, Moacir Roberto. Lixo rural: do problema à solução. ComCiência, n. 95, fev. 2008. Disponível em: https://www.comciencia.br/comciencia/handler.php?section=8\&edicao=32\&id=373\#: :text=Todavia\%2C\%20pa rte\%20consider\%C3\%A1vel\%20do\%20problema,apenas $\% 2020 \% 25 \% 20 \mathrm{dos} \% 20 \mathrm{domic} \% \mathrm{C} 3 \%$ ADlios\%20brasil eiros.\&text=No\%20in\%C3\%ADcio $\% 20 \mathrm{dessa} \% 20 \mathrm{~d} \% \mathrm{C} 3 \%$ A 9 cada $\% 2052$,rural $\% 20 \mathrm{era} \% 20$ enterrado $\% 20 \mathrm{ou} \% 20$ queimado.. Acesso em: 24 mar. 2017.

EIGENHEER, Emílio Maciel. Lixo: A limpeza Urbana Através dos Tempos. Porto Alegre: Palloti, 2009. Disponível em: http://www.lixoeeducacao.uerj.br/imagens/pdf/ahistoriadolixo.pdf. Acesso em: 27 fev. 2021.

FUNDAÇÃO DE ECONOMIA E ESTATÍSITCA - FEE. Censos Demográficos. Porto Alegre: FEE, 2013. Disponível em: https://www.dee.rs.gov.br/populacao. Acesso em: 31 mar. 2017.

INSTITUTO BRASILEIRO DE GEOGRAFIA E ESTATÍSITCA - IBGE. Censo Demográfico 2010. Rio de Janeiro: IBGE, 2010. Disponível em: https://www.ibge.gov.br/estatisticas/sociais/populacao/9662-censodemografico-2010.html?=\&t=o-que-e. Acesso em: 2 ago. 2017.

INSTITUTO DE PESQUISA ECONÔMICA APLICADA - IPEA. Diagnóstico dos Resíduos Sólidos Urbanos - Relatório de Pesquisa. Brasília: IPEA, 2012. Disponível em:

http://www.ipea.gov.br/agencia/images/stories/PDFs/relatoriopesquisa/121009_relatorio_residuos_solidos_urban os.pdf. Acesso em: 2 ago. 2017.

JACOBI, Pedro (Org). Gestão Compartilhada dos Resíduos Sólidos no Brasil: inovação com inclusão social. São Paulo: Annablume, 2006.

LEOPARDI, Maria Tereza et al. Metodologia da Pesquisa na Saúde. Santa Maria: Pallotti, 2001.

NOBRE, Márcio V.; COLLARES, Eduardo G. Recuperação de uma área degradada por erosão e disposição de resíduos sólidos na comunidade de Guardinha - município de São Sebastião do Paraíso (MG). Revista Ciência Et Praxis, Passos, n. 4, p. 31-36, jan. 2009. Disponível em:

http://tga.blv.ifmt.edu.br/media/filer_public/d9/2d/d92d1f44-115f-4422-8e70-826269ceeb1e/ rad_por_erosao_e_disposicao_de_residuos.pdf. Acesso em: 25 mar. 2017.

PEDROSO, Enio Fernando Höehr. Destinação e Armazenagem de Resíduos Sólidos em Propriedades Rurais. 2010. 46 f. Trabalho de Conclusão de Curso (Graduação em Administração) - Universidade Federal de Santa Cruz do Sul, 2010.

REICHERT, Geraldo Antônio. Gerenciamento de Resíduos Sólidos: uma proposta inovadora. Revista Ciência \& Ambiente, Santa Maria, ed. 18, jan./jun. 1999.

ROCHA, Adilson C. et al. Gestão de Resíduos Sólidos Domésticos na Zona Rural: A Realidade do Município de Pranchita - PR. Revista de Administração da UFSM, v. 5, n. 4, p. 699-714, dez. 2012. Disponível em: https://periodicos.ufsm.br/reaufsm/article/view/7657 ?source=/reaufsm/ article/view/7657. Acesso em: 25 maio 2017.

SANTA CRUZ DO SUL. Edital de Concorrência n⿳0 40/07. Secretaria Municipal da Fazenda, Divisão de Licitações, 2007.

SANTA CRUZ DO SUL. Plano Municipal de Gestão Integrada de Resíduos Sólidos. Santa Cruz do Sul, RS, 2013. Disponível em: http://portal.sysnova.com.br/Index.aspx. Acesso em: 27 mar. 2017.

\section{POLÊM!CA $\mid$ LABORE}

Polêmica - Revista Eletrônica da Uerj - Rua São Francisco Xavier, 524, $1^{\circ}$ andar bloco D, sl.1001 • Tels.: +55 21 2334-4088 / 4087 • http://www.e-publicacoes.uerj.br/index.php/polemica/index http://www.labore.uerj.br • laboreuerj@yahoo.com.br 
SANTA CRUZ DO SUL. Avaliação das Metas e Ações do PMGIRS de Santa Cruz do Sul-RS. Secretaria Municipal de Meio Ambiente, Saneamento e Sustentabilidade, Departamento de Controle e Qualidade Ambiental. Santa Cruz do Sul, RS: FACS, 2015.

SOARES, Lourdes da Silva et al. Lixo Rural: Classificação, Reciclagem e Destino Final do Resíduos Sólidos em Comunidades Rurais do Município de Cabaceiras-PB. In: Conferência Internacional de Gestão de Resíduos na América Latina - GRAL, 3., 2013, São Paulo. Anais... São Paulo: GRAL, 2013.

ZANETI, Izabel C. B. B. As sobras da Modernidade: O sistema de gestão de resíduos sólidos em Porto Alegre. Porto Alegre: [s.n.], 2006.

Recebido em: 01/05/2020.

Aceito em: 13/09/2021.

\section{POLÊM!CA $\mid$ LABORE}

